\title{
Cardiovascular and Gastrointestinal Safety of NSAIDs: A Systematic Review of Meta-Analyses of Randomized Clinical Trials
}

\author{
F Salvo ${ }^{1,2,3}$, A Fourrier-Réglat ${ }^{1,2,4,5}$, F Bazin ${ }^{1,2,5}$, P Robinson ${ }^{1,5}$, N Riera-Guardia ${ }^{6}, \mathrm{M} \mathrm{Haag}^{7}$, AP Caputi $^{3}$, \\ N Moore ${ }^{1,2,4,5}$, MC Sturkenboom ${ }^{7}$ and A Pariente ${ }^{1,2,4,5}$; on behalf of investigators of the Safety \\ of Non-Steroidal Anti-Inflammatory Drugs: The SOS Project
}

As part of the Safety of Non-Steroidal Anti-Inflammatory Drugs (SOS) Project, we reviewed the incidence of cardiovascular (CV) and gastrointestinal (GI) events associated with the use of this category of drugs. We collected data from published meta-analyses (MAs) of clinical trials of nonsteroidal anti-inflammatory drugs (NSAIDs). The Medline, Cochrane, ISI, and SCOPUS databases were systematically searched for MAs of NSAID clinical trials that could potentially contain data on adverse incidents such as myocardial infarction (MI), cerebrovascular events (CeVs), stroke, thromboembolic events (ThEs), heart failure (HF), gastrointestinal bleeding (GIB), and perforation, ulcer, and bleeding (PUB). From 1,733 identified references, 29 MAs were selected for the review. This allowed 109 estimations of incidence rates of CV adverse events and 26 estimations of incidence rates for GI adverse events. No data were found on hemorrhagic stroke or LGIB. Coxibs were studied in more MAs than traditional NSAIDs were (21 MAs for coxibs vs. 7 for traditional NSAIDs; one meta-analysis studied both). Many NSAIDs were not considered in any of the MAs. Our systematic review of MAs included information on the incidence of $\mathrm{CV}$ and $\mathrm{Gl}$ events and identified important knowledge gaps regarding, in particular, the CV safety of traditional NSAIDs.

After the discovery in the early 1990s of at least two isoenzymes of cyclooxygenase (COX-I and COX-II), selective COX-II inhibitors (coxibs) were developed as safer alternatives to nonselective, traditional nonsteroidal anti-inflammatory drugs (tNSAIDs). ${ }^{1}$ This development was based on the assumption that coxibs would have analgesic and anti-inflammatory efficacy similar to that of tNSAIDs (because of the expected mediation by the COX-II isoenzyme), but a lower associated risk of gastrointestinal (GI) adverse events.

Because the data submitted for marketing authorization of the first coxibs did not provide definite evidence of significant reduction in the incidence of serious GI events, large postapproval randomized clinical trials (RCTs) were initiated to study the GI benefits of these drugs in comparison with selected tNSAIDs. ${ }^{2,3}$ These studies generated some concerns about the cardiovascular (CV) safety profile of coxibs, especially of rofecoxib, and led to the reconsideration of their benefit/risk ratio. Subsequent investigations led to the primary hypothesis that the thrombotic risk was related to the thromboxane/prostacycline imbalance induced by the COX-II inhibition. 4

To date, there is insufficient knowledge regarding GI and CV risks associated with the use of each of the NSAIDs in terms of duration and dose, particularly in high-risk patients. In this context, and at the request of the European Medicines Agency, the European Commission funded the Safety of Non-Steroidal Anti-Inflammatory Drugs (SOS) collaborative project (FP7 grant agreement: 223495) (http://www.sos-nsaids-project. org). This project comprises a consortium of 12 research groups from seven European countries. The overall objective of the SOS project is to assess and compare the risk of GI and CV events associated with the use of NSAIDs (tNSAIDs and coxibs). The ultimate goal of this project is to develop clinical decision models to allow for more personalized NSAID therapy in light of the predicted GI and CV risks.

The efficacy of NSAIDs has been evaluated through a large number of RCTs, allowing numerous pooled analyses and meta-analyses (MAs) to be conducted for studying the efficacy

\footnotetext{
${ }^{1}$ Département de Pharmacologie, Université de Bordeaux, Bordeaux, France; ${ }^{2}$ INSERM U657, Bordeaux, France; ${ }^{3}$ Dipartimento Clinico Sperimentale di Medicina e Farmacologia, Università di Messina, Messina, Italy; ${ }^{4} \mathrm{CHU}$ de Bordeaux, Bordeaux, France; ${ }^{5}$ INSERM CIC 0005, Bordeaux, France; ${ }^{6} \mathrm{RTI}$-Health Solutions, Barcelona, Spain; ${ }^{7}$ Department of Medical Informatics, Erasmus University Medical Centre, Rotterdam, The Netherlands. Correspondence: F Salvo (francesco.salvo@u-bordeaux2.fr) 


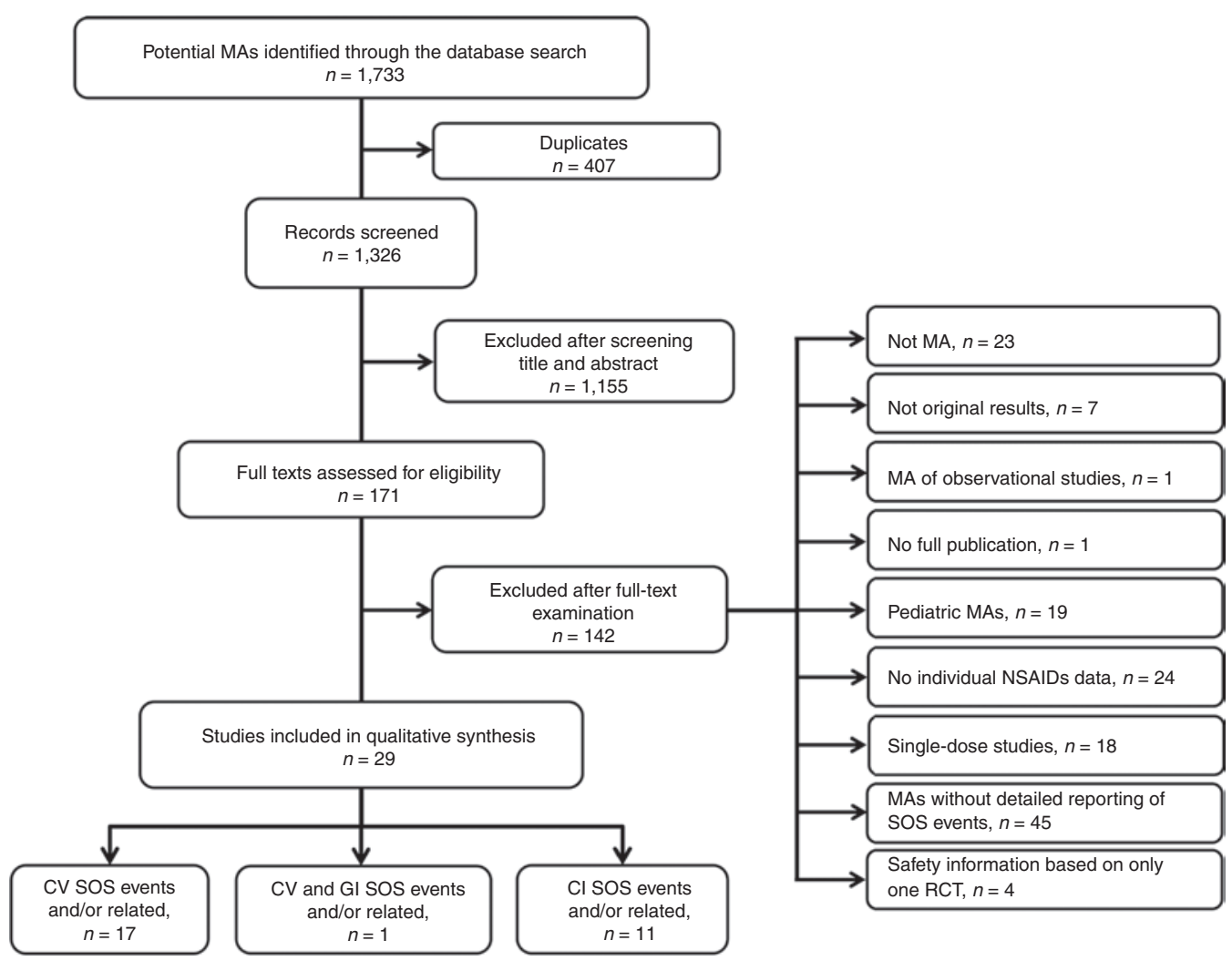

Figure 1 Flow diagram of process of selecting MAs. CV, cardiovascular; Gl, gastrointestinal; MAs, meta-analyses; NSAIDs, nonsteroidal anti-inflammatory drugs; $\mathrm{RCT}$, randomized controlled trial; SOS, safety of nonsteroidal anti-inflammatory drugs.

and safety of these drugs. In the context of evidence-based medicine, MAs are thought to represent the highest methodological level of quality for the comparative evaluation of drugs. They enable a more objective and systematic appraisal of the evidence than do traditional narrative reviews. A more precise estimate of a treatment effect is obtained by combining estimates from single RCTs. ${ }^{5}$ To synthesize the information on absolute risks of GI and CV adverse events associated with the use of individual NSAIDs in RCTs, and to identify knowledge gaps in the safety evaluation of these drugs, a systematic quantitative review of the MAs on NSAID RCTs was conducted.

\section{RESULTS}

\section{Selection of MAs}

Database searches identified 1,733 potentially relevant MAs, of which 407 were duplicates and therefore excluded. Another 1,155 MAs were excluded because their abstracts revealed that they did not meet the inclusion criteria of our study. The remaining 171 MAs were read in full and evaluated independently by two authors (F.S. and A.P.); of these, 142 were excluded (see Supplementary Appendix 1 online) for the following reasons: not an MA $(n=23)(\mathrm{a} 1-\mathrm{a} 23)$, no original results $(n=7)(\mathrm{a} 24-$ a30), MA of observational studies $(n=1)$ (a31), no full publication $(n=1)$ (a32), MAs on pediatric populations only $(n=19)$ (a33-a51), no data for individual NSAIDs $(n=24)$ (a52-75), MAs including a majority of RCTs of single-dose NSAID use $(n=18)$ (a76-93), MAs reporting nonspecific events (i.e., GI symptoms or CV events) ( $n=45)$ (a94-138), and information based on one RCT only $(n=4)($ a139-142).

A total of 29 MAs were included in the review. ${ }^{6-34}$ According to the QUOROM (Quality of Reports of Meta-Analyses) checklist, the methodological quality of these was generally good, although in three of the MAs the methods employed were not sufficiently detailed. ${ }^{7,8,28}$ Of the 29 MAs selected, 17 reported on CV events, 11 on GI events, and 1 on both CV and GI events (Figure 1).

The 29 MAs retained in the review made reference to a total of 496 reports, of which 85 could not be identified. The 411 identifiable reports corresponded to 204 independent articles. The number of RCTs included in various MAs ranged from 2 to 72 , and the number of patients from 117 to 34,688 (120.6-25,836 person-years (PYs) when reported). The drugs investigated in the retained MAs were rofecoxib (nine MAs), celecoxib (seven MAs), etoricoxib (seven MAs), valdecoxib (five MAs), meloxicam (five MAs), lumiracoxib (four MAs), aspirin (two MAs), parecoxib/ valdecoxib combined, etodolac, and nabumetone (one MA each). The MAs included RCTs that evaluated NSAIDs in either one or several indications (7 and 23 MAs, respectively) (Table 1). The most frequently studied indications for the use of NSAIDs were osteoarthritis (23 MAs), rheumatoid arthritis (20 MAs), and chronic low back pain (3 MAs). The characteristics of the NSAIDs used as reference drugs in the RCTs selected in retained MAs are provided in Table 2. Estimates of cumulative incidence (\%) and/or incidence rates (\% PYs) for GI and CV events are 
Table 1 Characteristics of MAs included in this review regarding the nonsteroidal anti-inflammatory drug (NSAID) or NSAIDs of interest

\begin{tabular}{|c|c|c|c|c|c|c|c|c|c|}
\hline \multirow[b]{2}{*}{ Drugs } & \multirow[b]{2}{*}{ MAs } & \multicolumn{4}{|c|}{ Estimates } & \multicolumn{4}{|c|}{ RCTs considered for estimates } \\
\hline & & Events & Control & Patients & PYs & Number & $\begin{array}{c}\text { Duration, } \\
\text { weeks (range) }\end{array}$ & $\begin{array}{l}\text { Dose, mg } \\
\text { (range) }\end{array}$ & Indications \\
\hline \multicolumn{10}{|l|}{ Coxibs } \\
\hline \multirow[t]{12}{*}{ Celecoxib } & Caldwell et al. ${ }^{8}$ & $\mathrm{MI}$ & Placebo & 2,574 & & 4 & \multirow{4}{*}{$>6$} & \multirow{4}{*}{$(200-800)$} & \multirow{4}{*}{ CRP, OA, PAD, RA } \\
\hline & & & Active & 6,658 & & 6 & & & \\
\hline & & $\mathrm{CeV}$ & Placebo & 2,775 & & 4 & & & \\
\hline & & & Active & 6,859 & & 6 & & & \\
\hline & \multirow[t]{2}{*}{ Chen et al. ${ }^{10}$} & \multirow[t]{2}{*}{$\mathrm{CeV}$} & Placebo & 2,574 & & 3 & $(52-161)$ & $(400-800)$ & OA, PAD, RA \\
\hline & & & Active & 14,430 & & 6 & $(6-52)$ & $(100-800)$ & $\mathrm{OA}, \mathrm{RA}$ \\
\hline & \multirow[t]{2}{*}{ Chen et al. ${ }^{11}$} & \multirow[t]{2}{*}{$\mathrm{Ml}$} & Placebo & 5,632 & & 8 & $(6-161)$ & $(200-800)$ & CLBP, CRP, OA, PAD \\
\hline & & & Active & 17,678 & & 13 & $(12-52)$ & $(100-800)$ & CLBP, OA, RA \\
\hline & Kearney et al..$^{22}$ & MI, stroke & Placebo & & 8,976 & 41 & $(4-156)$ & $(25-800)$ & $\begin{array}{l}\text { AF, AS, CLBP, CRP, OA, PAD, } \\
\text { RA, TMJP, other }\end{array}$ \\
\hline & Moore et al. ${ }^{26}$ & $\mathrm{Ml}, \mathrm{HF}$ & $\begin{array}{l}\text { Placebo } \\
\text { Active }\end{array}$ & $\begin{array}{r}7,072 \\
20,435\end{array}$ & & $\begin{array}{l}17 \\
27\end{array}$ & $\begin{array}{l}(2-12) \\
(6-52)\end{array}$ & $\begin{array}{l}(80-800) \\
(100-800)\end{array}$ & $\mathrm{OA}, \mathrm{RA}$ \\
\hline & Solomon et al..$^{30}$ & MI, stroke, FS & Placebo & 2,289 & & 2 & 160 & $(200-800)$ & CRP \\
\hline & White et al..$^{33}$ & $\mathrm{Ml}$, stroke, FS & $\begin{array}{l}\text { Placebo } \\
\text { Active }\end{array}$ & $\begin{array}{r}4,849 \\
12,449\end{array}$ & $\begin{array}{r}700 \\
2,422\end{array}$ & $\begin{array}{l}6 \\
7\end{array}$ & $\begin{array}{r}(4-12) \\
(12-26)\end{array}$ & $\begin{array}{l}(25-400) \\
(50-400)\end{array}$ & $\mathrm{OA}, \mathrm{RA}$ \\
\hline \multirow[t]{9}{*}{ Etoricoxib } & Aldington et al. ${ }^{6}$ & ThE & Placebo & 1,441 & & 5 & $(6-12)$ & $(30-90)$ & CLBP, OA, RA \\
\hline & Cannon et al..$^{9}$ & $\mathrm{Ml}, \mathrm{CeV}$ & Active & 16,819 & 25,836 & 3 & 78 & $(60-90)$ & $\mathrm{OA}, \mathrm{RA}$ \\
\hline & Chen et al. ${ }^{12}$ & PUB & $\begin{array}{l}\text { Placebo/ } \\
\text { active }\end{array}$ & 900 & & 3 & 12 & $(60-90)$ & $\mathrm{OA}, \mathrm{RA}$ \\
\hline & Chen et al. ${ }^{11}$ & $\mathrm{Ml}$ & Active & 4,165 & & 3 & $(12-48)$ & $(90-120)$ & OA, RA, AS \\
\hline & \multirow[t]{3}{*}{ Curtis et al. ${ }^{13}$} & \multirow[t]{2}{*}{ MI, CeV, IS, ThE } & Active & 1,266 & 1,522 & 4 & $(12-190)$ & $(30-120)$ & OA, RA \\
\hline & & & Active & 1,960 & 2,480 & \multirow{2}{*}{6} & \multirow{2}{*}{$(12-138)$} & \multirow{2}{*}{$(60-120)$} & \multirow{2}{*}{ OA, RA, AS } \\
\hline & & ThE & Placebo & 2,818 & 560 & & & & \\
\hline & Kearney et al. ${ }^{22}$ & MI, stroke & Placebo & & 753 & 17 & $(6-190)$ & $(30-120)$ & CLBP, OA, RA, AS, other \\
\hline & Ramey et al..27 & PUB & Active & 3,226 & $4,001.65$ & 10 & $(12-190)$ & $(5-120)$ & OA, RA, AS \\
\hline \multirow[t]{9}{*}{ Lumiracoxib } & Chen et al. ${ }^{10}$ & $\mathrm{CeV}$ & Placebo & 1,606 & & 3 & $(13-26)$ & $(100-400)$ & \\
\hline & & & Active & 10,508 & & 5 & $(26-52)$ & $(200-400)$ & OA, RA \\
\hline & Chen et al. ${ }^{11}$ & $\mathrm{Ml}$ & $\begin{array}{l}\text { Placebo } \\
\text { Active }\end{array}$ & $\begin{array}{r}3,903 \\
11,569\end{array}$ & & $\begin{array}{l}6 \\
8\end{array}$ & $\begin{array}{r}(13-26) \\
(4-52)\end{array}$ & $\begin{array}{c}(100-400) \\
(200-1,200)\end{array}$ & $\mathrm{OA}, \mathrm{RA}$ \\
\hline & Kearney et al. ${ }^{22}$ & $\mathrm{MI}$, stroke & Placebo & & 1,375 & 12 & $(4-52)$ & $(100-1,200)$ & OA, RA \\
\hline & Matchaba et al. ${ }^{25}$ & $\mathrm{MI}$, stroke & Placebo & 7,011 & $1,969.2$ & 14 & $(1-13)$ & $(50-400)$ & \\
\hline & & & Active & 24,312 & $6,721.6$ & 19 & $(1-52)$ & $(30-400)$ & \\
\hline & & & Active & 5,964 & $8,054.4$ & 5 & $(4-52)$ & $(200-1,200)$ & $\mathrm{OA}, \mathrm{RA}$ \\
\hline & & & Active & 6,126 & & 18 & (1) 52$)$ & $(50-800)$ & \\
\hline & & & Active & 34,688 & & 22 & $(1-52)$ & $(50-1,200)$ & \\
\hline $\begin{array}{l}\text { Parecoxib/ } \\
\text { valdecoxib }\end{array}$ & Aldington et al. ${ }^{7}$ & $\mathrm{Ml}, \mathrm{CeV}$ & Placebo & 1,380 & & 3 & 2 & NR & PCB \\
\hline Rofecoxib & Chen et al. ${ }^{12}$ & PUB & $\begin{array}{l}\text { Placebo/ } \\
\text { active }\end{array}$ & 9,201 & & 8 & $(6-52)$ & $(12.5-50)$ & OA, RA \\
\hline & Chen et al. ${ }^{10}$ & $\mathrm{CeV}$ & Placebo & 4,058 & & 8 & $(6-208)$ & $(12.5-25)$ & OA, PAD, CRP \\
\hline & & & Active & 9,954 & & 11 & $(6-86)$ & $(12.5-50)$ & OA, RA \\
\hline & Chen et al. ${ }^{11}$ & $\mathrm{Ml}$ & Placebo & 5,413 & & 8 & $(6-208)$ & $(12550)$ & OA, CLBP, PAD, CRP \\
\hline & & & Active & 9,241 & & 11 & $(6-86)$ & $(12.5-5 U)$ & OA, PAD \\
\hline & Garner et al. ${ }^{18}$ & $\mathrm{HF}$ & Active & 1,133 & & 3 & 6 & $(125-25)$ & \\
\hline & & PUB & Placebo & 2,245 & & 6 & 0 & $(12.3-23)$ & \\
\hline & & & Active & 3,256 & & & $(6-12)$ & $(12.5-25)$ & \\
\hline & & & Active & 285 & & & 6 & 25 & $\mathrm{OA}$ \\
\hline & & & Active & 3,225 & & 2 & $(6-12)$ & & \\
\hline & & & Active & 677 & & & 6 & $(12.5-25)$ & \\
\hline & & & Active & 932 & & & 0 & & \\
\hline
\end{tabular}


Table 1 (Continued)

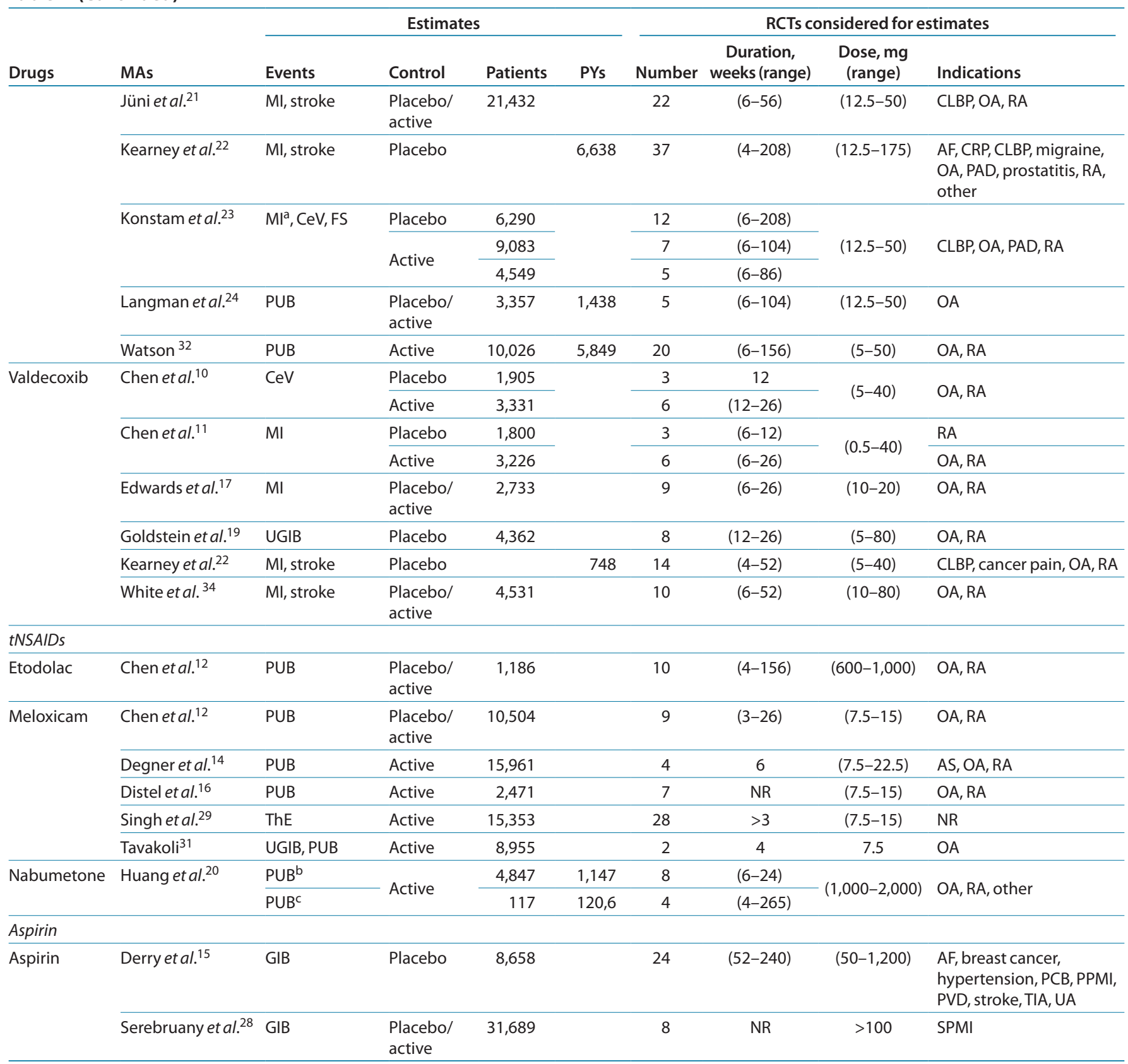

Cardiovascular events: CeV, cerebrovascular event; FS, fatal stroke; HF, heart failure; IS, ischemic stroke; MI, myocardial infarction; ThE, thromboembolic event.

Gastrointestinal events: GIB, gastrointestinal bleeding; PUB, perforation, ulcer, and bleeding; UGIB, upper gastrointestinal bleeding.

Indications: AF, atrial fibrillation; AS, ankylosing spondylitis; $C L B P$, chronic low back pain; CRP, colorectal polyps; OA, osteoarthritis; PAD, prevention of Alzheimer's disease; PCB, postcoronary bypass; POP, postoperative pain; PPMI, primary prevention of myocardial infarction; PVD, peripheral vascular disease; RA, rheumatoid arthritis; SPMI, secondary prevention of MI or unstable angina; TIA, transient ischemic attack; TMJP, temporomandibular joint pain; UA, unstable angina; NR, not retrievable.

Trial duration: NR, not retrievable.

${ }^{\mathrm{a}} \mathrm{MI}$ data were retrieved by pooling the number of fatal MI and nonfatal cardiac events (i.e., patients with nonfatal MI or those resuscitated after a cardiac arrest). ${ }^{\mathrm{b}} \mathrm{Nonendoscopic}$

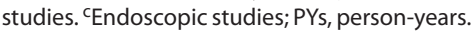

shown as graphs in Figures 2 and 3 and in Supplementary Figures S1-S3 online, and 95\% confidences intervals (95\% CI) are listed in Supplementary Appendix 2 online. In all but one of the MAs, the incidence of adverse events was calculated from the number of patients or PYs and events reported in the full text. In the MA by Moore et al., ${ }^{26}$ the number of patients was retrieved from supplementary material, and the cumulative incidence reported in the full text was used in our analysis.

\section{Incidence estimates of CV events}

Myocardial infarction (MI). From the MAs that provided data on MI $(n=14), 45$ incidence estimates could be calculated; 
Table 2 Characteristics of MAs included in this review regarding the reference nonsteroidal anti-inflammatory drug (NSAID) or NSAIDs Estimates

RCTs considered for estimations

Duration, Dose, $\mathrm{mg}$

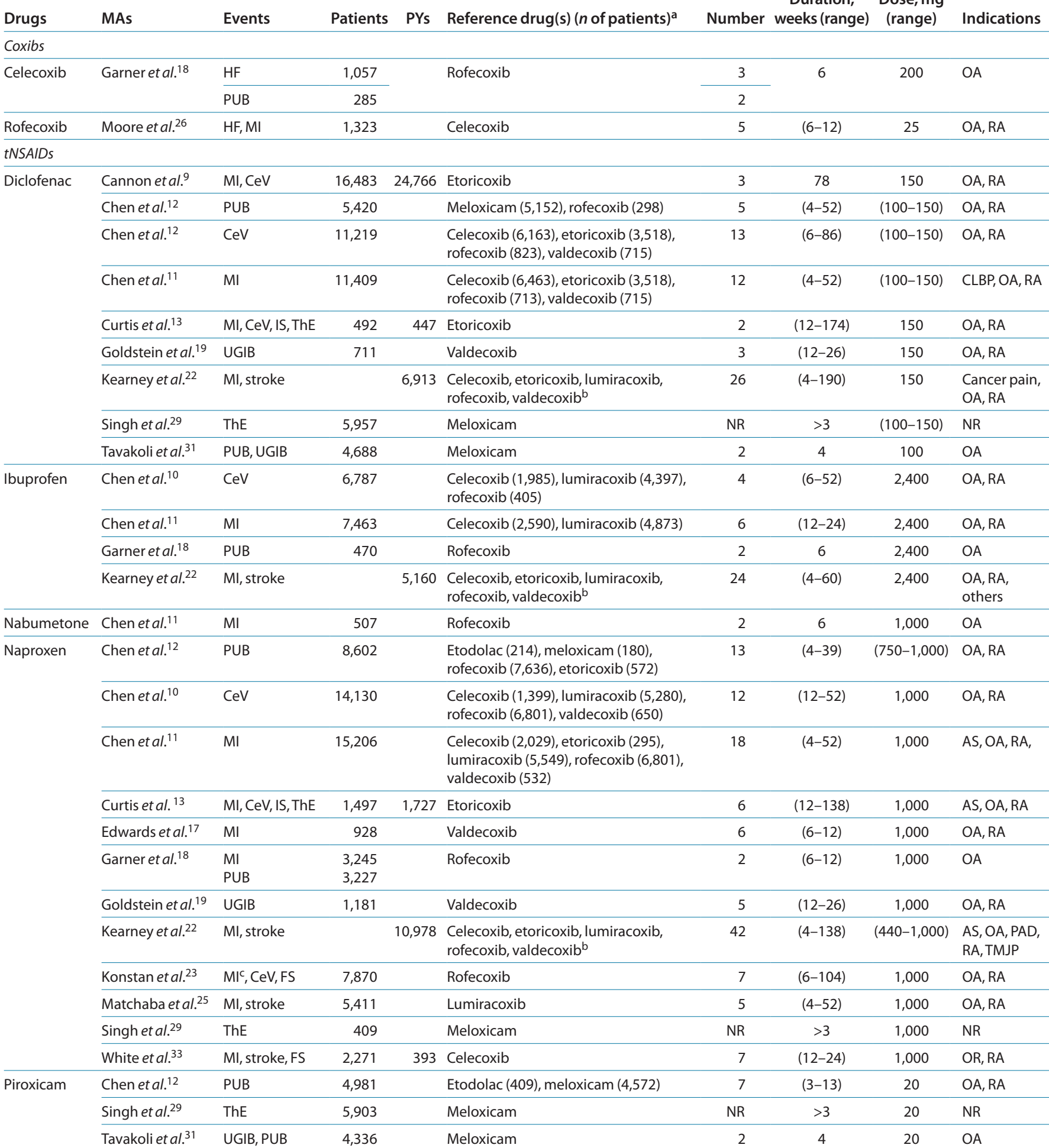

Cardiovascular events: $\mathrm{CeV}$, cerebrovascular event; $\mathrm{FS}$, fatal stroke; $\mathrm{HF}$, heart failure; IS, ischemic stroke; $\mathrm{MI}$, myocardial infarction; ThE, thromboembolic event.

Gastrointestinal events: GIB, gastrointestinal bleeding; PUB, perforation, ulcer, and bleeding; UGIB, upper gastrointestinal bleeding.

Indications: AS, ankylosing spondylitis; CLBP, chronic low back pain; NR, not retrievable; $\mathrm{OA}$, osteoarthritis; $\mathrm{PAD}$, prevention of Alzheimer's disease; RA, rheumatoid arthritis; TMJP, temporomandibular joint pain

Trial duration: NR, not retrievable.

${ }^{a}$ Number of patients treated with the drug for each reference NSAID. b Number of patients was not retrievable. ${ }^{\mathrm{C}} \mathrm{Ml}$ data were retrieved by pooling the number of fatal MI and nonfatal cardiac events (i.e., patients with nonfatal Ml or those resuscitated after a cardiac arrest). 


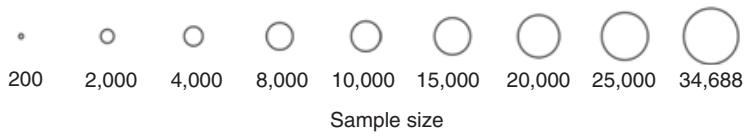

a

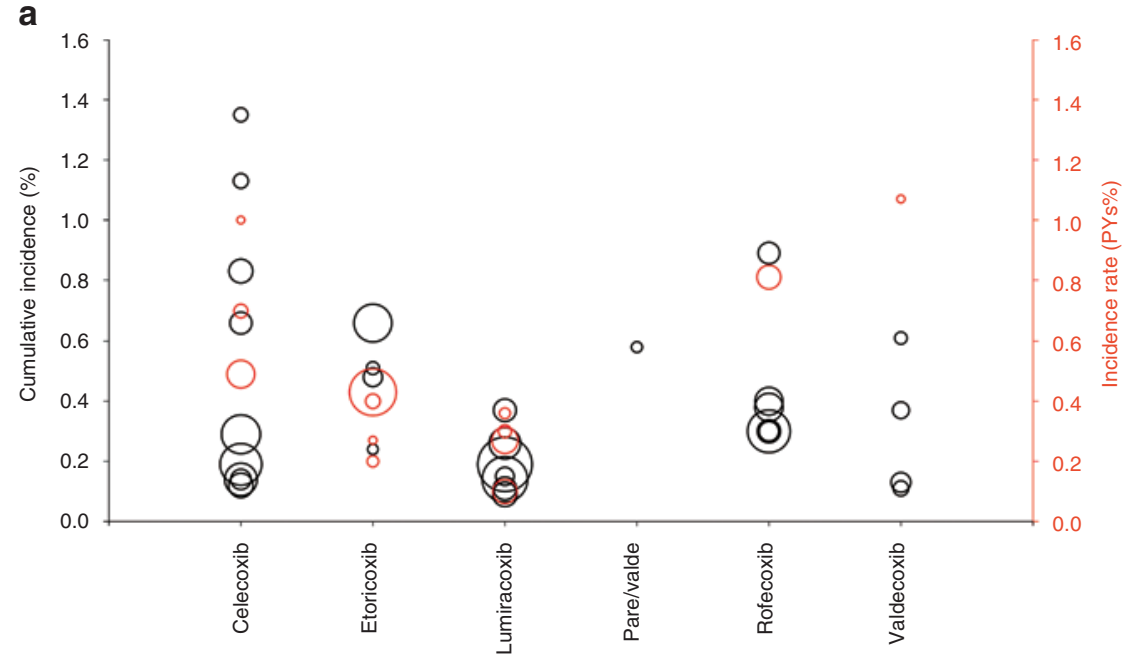

\begin{tabular}{|c|c|c|c|c|c|c|c|c|c|c|c|c|c|c|c|c|c|}
\hline \multicolumn{3}{|c|}{ Celecoxib } & \multicolumn{3}{|c|}{ Etoricoxib } & \multicolumn{3}{|c|}{ Lumiracoxib } & \multicolumn{3}{|c|}{ Parecoxib/valdecoxib } & \multicolumn{3}{|c|}{ Rofecoxib } & \multicolumn{3}{|c|}{ Valdecoxib } \\
\hline $\begin{array}{c}\text { Rate } \\
(\%)\end{array}$ & Control & Ref. & $\begin{array}{c}\text { Rate } \\
(\%)\end{array}$ & Control & Ref. & $\begin{array}{c}\text { Rate } \\
(\%)\end{array}$ & Control & Ref. & $\begin{array}{c}\text { Rate } \\
(\%)\end{array}$ & Control & Ref. & $\begin{array}{c}\text { Rate } \\
(\%)\end{array}$ & Control & Ref. & $\begin{array}{l}\text { Rate } \\
(\%)\end{array}$ & Control & Ref. \\
\hline 1.35 & Placebo & (31) & 0.66 & Active & (10) & 0.37 & Active & (26) & 0.58 & Placebo & (8) & 0.89 & Placebo & (12) & 1.07 & Placebo & (23) \\
\hline 1.13 & Placebo & (9) & 0.51 & Active & (14) & 0.36 & Placebo & (23) & & & & 0.81 & Placebo & (23) & 0.61 & Placebo & (12) \\
\hline 1.00 & Placebo & (34) & 0.48 & Active & (12) & 0.30 & Active & (26) & & & & 0.40 & Active & (24) & 0.37 & Active & (12) \\
\hline 0.83 & Active & (9) & 0.43 & Active & (10) & 0.27 & Active & (26) & & & & 0.38 & Active & (12) & 0.13 & Placebo & (35) \\
\hline 0.70 & Active & (34) & 0.40 & Active & (14) & 0.26 & Active & (12) & & & & 0.30 & Placebo & (24) & 0.11 & Active & (18) \\
\hline 0.66 & Placebo & (12) & 0.31 & Placebo & (12) & 0.19 & Active & (26) & & & & 0.30 & Active & (24) & & & \\
\hline 0.49 & Placebo & (23) & 0.27 & Placebo & (23) & 0.15 & Placebo & (12) & & & & 0.30 & Active & (22) & & & \\
\hline 0.29 & Active & (12) & 0.24 & Active & (14) & 0.14 & Active & (26) & & & & & & & & & \\
\hline 0.19 & Active & (27) & 0.20 & Active & (14) & 0.11 & Active & (26) & & & & & & & & & \\
\hline 0.14 & Placebo & (34) & & & & 0.10 & Active & (26) & & & & & & & & & \\
\hline 0.14 & Active & (34) & & & & 0.09 & Placebo & (26) & & & & & & & & & \\
\hline 0.12 & Placebo & (27) & & & & & & & & & & & & & & & \\
\hline
\end{tabular}

\section{b}

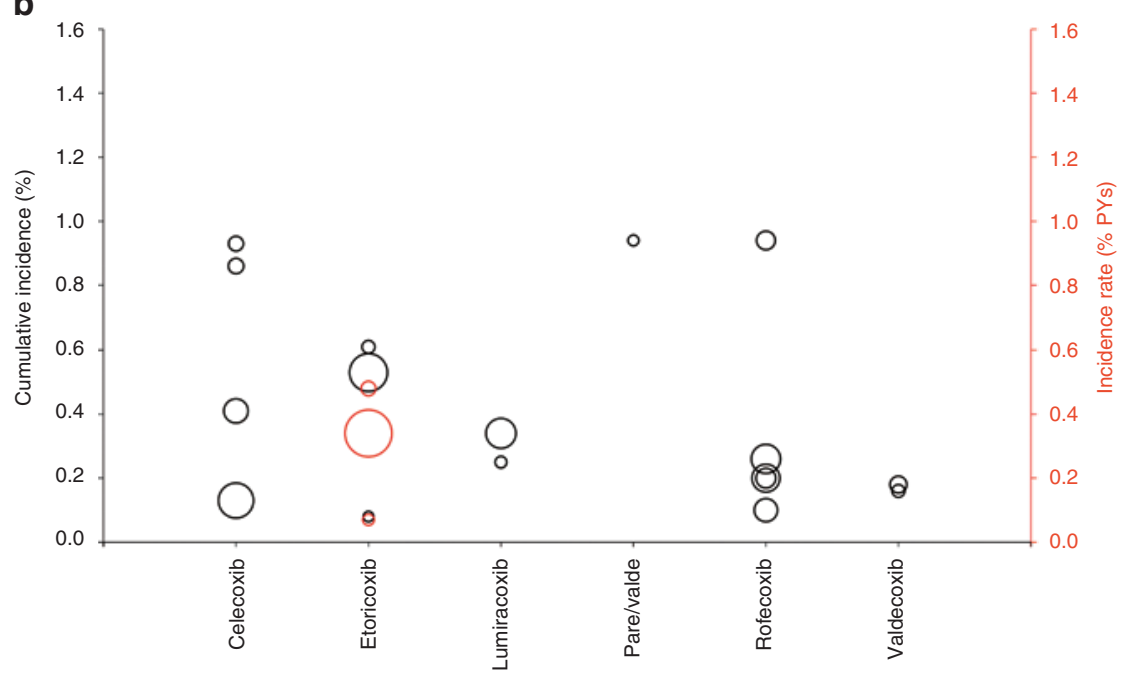

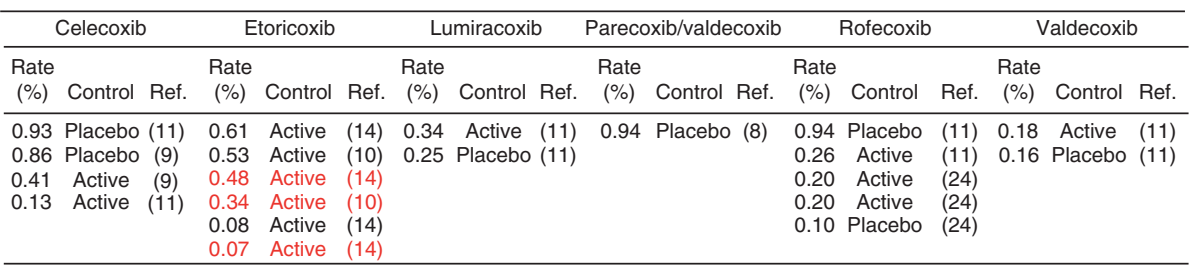

Figure 2 Continued on next page 


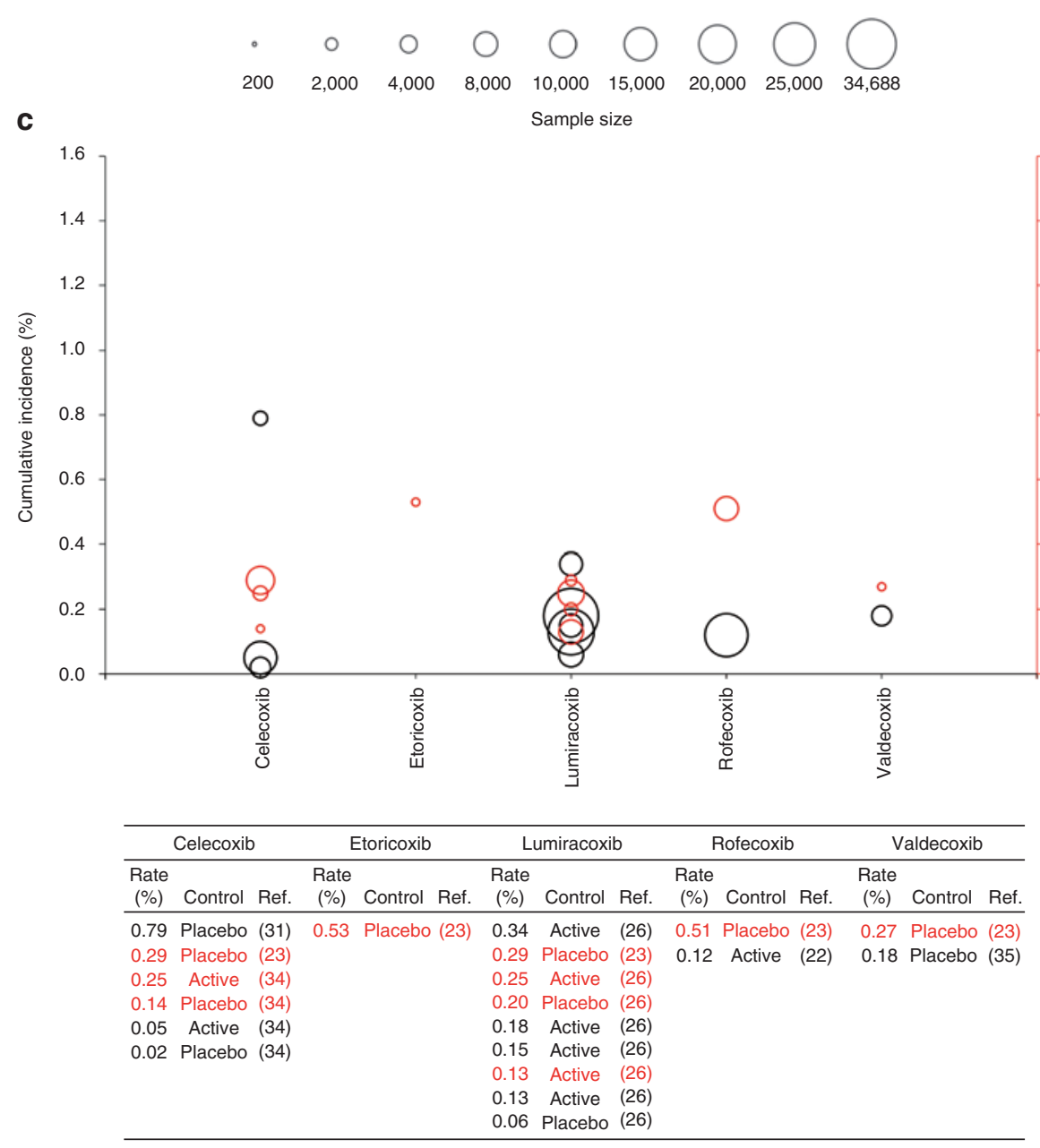

Figure 2 Myocardial infarction, cerebrovascular events, and stroke. Cumulative (black) and incidence (red) rates of (a) myocardial infarction (MI), (b) cerebrovascular events, and (c) stroke associated with the use of nonsteroidal anti-inflammatory drugs are shown. The plot shows incidence rates, and the diameter of the circle indicates the size of the population, as indicated below the plot. The table presents exact values and associated references. PYs, person-years.

the numbers of RCTs included ranged from 2 to 41 , and the duration of the trials ranged from 1 to 208 weeks (Figure 2a, Table 1).

Cumulative incidence rates for MI ranged from 0.12 to $1.35 \%$ for celecoxib, from 0.24 to $0.66 \%$ for etoricoxib, from 0.09 to $0.37 \%$ for lumiracoxib, from 0.30 to $0.89 \%$ for rofecoxib, and from 0.11 to $0.61 \%$ for valdecoxib; there was only one estimate for parecoxib/valdecoxib combined (0.58\%).

Incidence rates of MI ranged from 0.49 to $1.00 \%$ PYs for celecoxib, from 0.20 to $0.43 \%$ PYs for etoricoxib, and from 0.10 to $0.36 \%$ PYs for lumiracoxib; there was only one estimate each for rofecoxib (0.81\% PYs) and valdecoxib (1.07\% PYs).

Cerebrovascular events (CeVs). From the MAs that had data on any type of $\mathrm{CeV}(n=6), 20$ incidence estimations could be calculated; the number of RCTs included ranged from 3 to 12 , and the duration of the trials ranged from 2 to 208 weeks (Figure 2b, Table 1).

Cumulative incidence rates of any kind of $\mathrm{CeV}$ ranged from 0.13 to $0.93 \%$ for celecoxib, from 0.08 to $0.61 \%$ for etoricoxib, from 0.25 to $0.34 \%$ for lumiracoxib, from 0.1 to $0.94 \%$ for rofecoxib, and from 0.16 to $0.18 \%$ for valdecoxib; there was only one estimate for parecoxib/valdecoxib (0.94\%).

Incidence rates of $\mathrm{CeVs}$ of any kind could be calculated only for celecoxib (0.07-0.48\% PYs).

Stroke. From the MAs that had data on the incidence of stroke $(n=6), 20$ estimates of incidence could be calculated; the number of RCTs included ranged from 2 to 41, and the trials ranged from 1 to 208 weeks in duration (Figure 2c, Table 1).

Cumulative incidence rates of stroke ranged from 0.02 to $0.79 \%$ for celecoxib and from 0.06 to $0.34 \%$ for lumiracoxib; there was only one estimate each for rofecoxib $(0.12 \%)$ and valdecoxib $(0.18 \%)$.

Incidence rates of stroke ranged from 0.14 to $0.29 \% \mathrm{PYs}$ for celecoxib and from 0.13 to $0.29 \%$ PYs for lumiracoxib; there was only one estimate each for etoricoxib (0.53\% PYs), rofecoxib (0.51\% PYs), and valdecoxib (0.27\% PYs).

Ischemic stroke (IS). From the MAs that had data on IS $(n=2)$, six incidence estimates could be calculated; the number of RCTs included ranged from four to six, and the duration of trials 


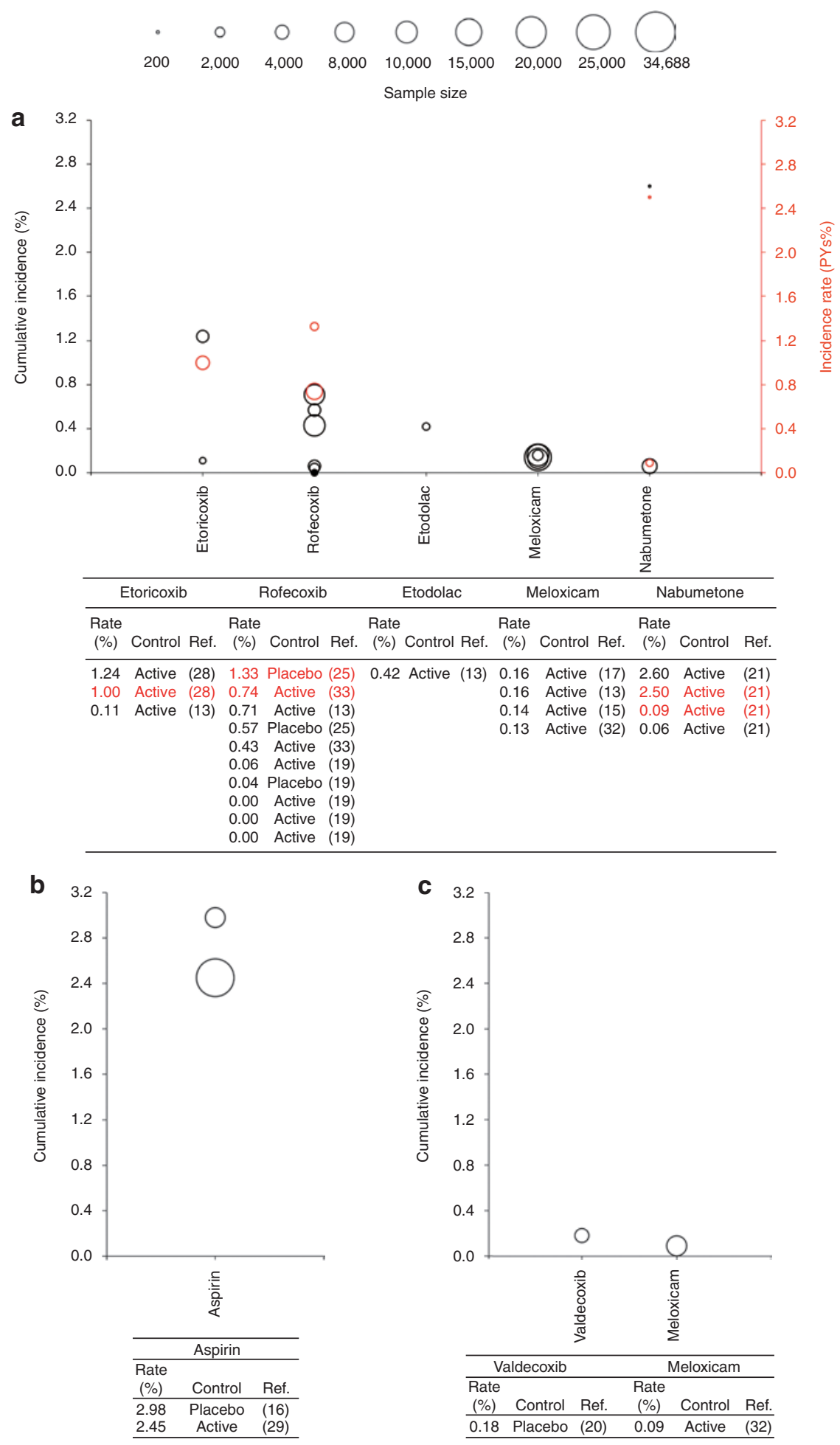

Figure 3 Perforation, ulcer, and bleeding, gastrointestinal (Gl) bleeding, and upper Gl bleeding. Cumulative (black) and incidence (red) rates of (a) perforation, ulcer, and bleeding, (b) Gl bleeding, and (c) upper Gl bleeding associated with the use of nonsteroidal anti-inflammatory drugs are shown. The plot shows incidence rates, and the diameter of the circle indicates the size of the population, as indicated below the plot. The tables present exact values and associated references.

ranged from 12 to 190 weeks (see Supplementary Figure S1a online, Table 1).

Data were available for etoricoxib only; for this drug, cumulative incidence rates ranged from 0.08 to $0.51 \%$, and incidence rates ranged from 0.07 to $0.40 \% \mathrm{PYs}$.
Fatal stroke (FS). From the MAs that had data on FS ( $n=3)$, eight incidence estimates could be calculated; the number of RCTs included ranged from 2 to 12 , and the duration of trials ranged from 4 to 208 weeks (see Supplementary Figure S1b online, Table 1). 
Table 3 Incidence estimates of selected cardiovascular (CV) events for reference nonsteroidal anti-inflammatory drugs (NSAIDs)

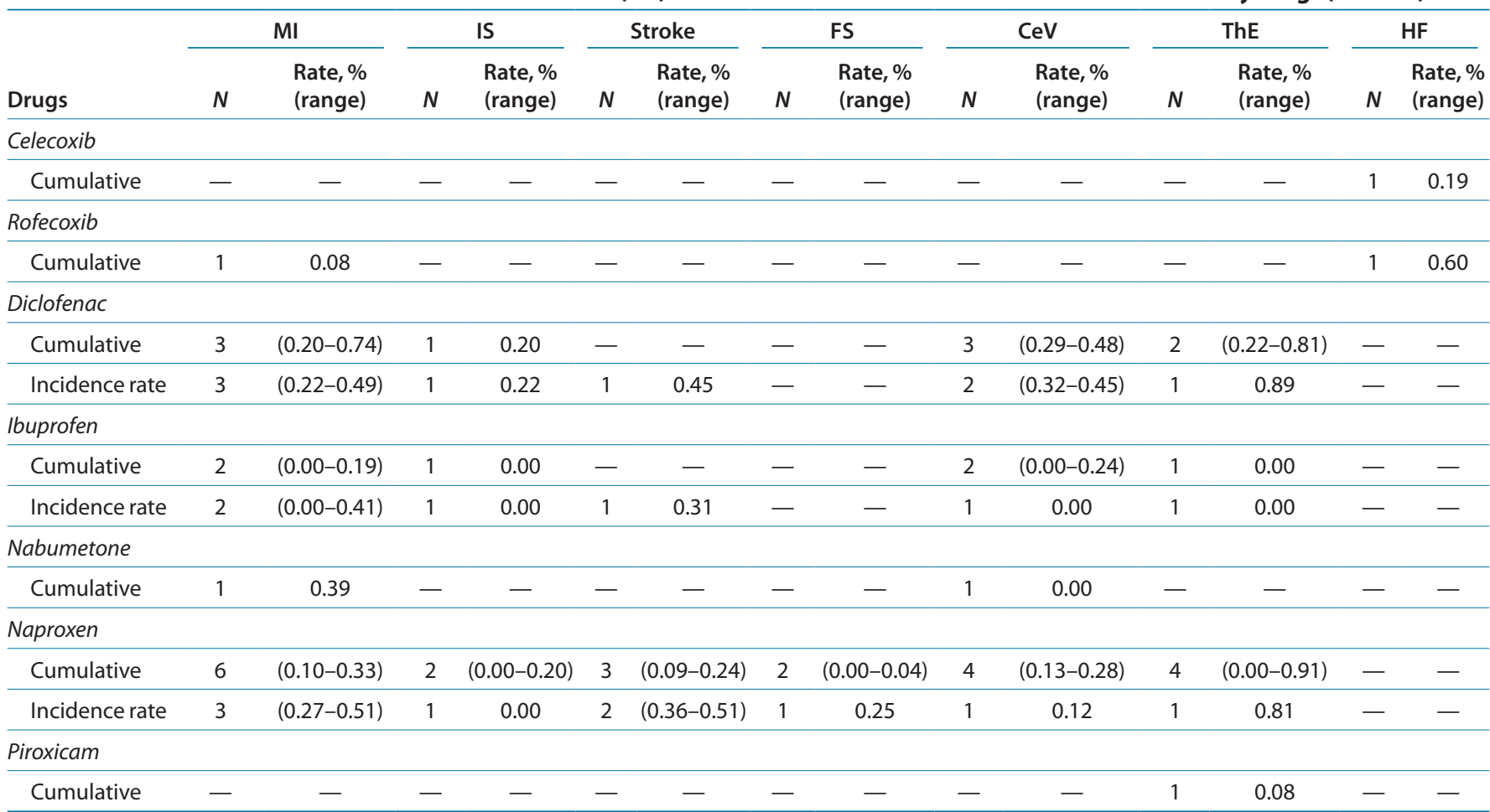

$\mathrm{CeV}$, cerebrovascular event; $\mathrm{FS}$, fatal stroke; $\mathrm{HF}$, heart failure; IS, ischemic stroke; MI, myocardial infarction; ThE, thromboembolic event.

Table 4 Incidence estimates of selected gastrointestinal (GI) events for reference nonsteroidal anti-inflammatory drugs (NSAIDs) (only cumulative incidence is provided)

\begin{tabular}{|c|c|c|c|c|c|c|}
\hline \multirow[b]{2}{*}{ Drugs } & \multicolumn{2}{|r|}{ UGIB } & \multicolumn{2}{|c|}{ GIB } & \multicolumn{2}{|c|}{ PUBs } \\
\hline & $N$ & $\begin{array}{l}\text { Rate, \% } \\
\text { (range) }\end{array}$ & $N$ & $\begin{array}{l}\text { Rate, \% } \\
\text { (range) }\end{array}$ & $N$ & $\begin{array}{l}\text { Rate, \% } \\
\text { (range) }\end{array}$ \\
\hline Celecoxib & - & - & - & - & 1 & 0.00 \\
\hline Diclofenac & 2 & $(0.04-0.56)$ & - & - & 6 & $(0.13-1.12)$ \\
\hline Etodolac & - & - & - & - & 1 & 0.42 \\
\hline Ibuprofen & 1 & 0.00 & - & - & 3 & $(0.55-2.16)$ \\
\hline Nabumetone & - & - & - & - & 1 & 0.00 \\
\hline Naproxen & 1 & 0.59 & 1 & 2.04 & 4 & $(0.37-3.00)$ \\
\hline Piroxicam & 1 & 0.21 & - & - & 4 & (0.37-1.16) \\
\hline
\end{tabular}

$\mathrm{GIB}$, gastrointestinal bleeding; PUB, perforation, ulcer, and bleeding; UGIB, upper gastrointestinal bleeding.

Cumulative incidence rates of FS ranged from 0 to $0.04 \%$ for celecoxib, and all estimates were zero (i.e., no FS event) for rofecoxib.

Incidence rates of FS were calculated for celecoxib only, and all estimates were zero.

Thromboembolic events (ThEs). From the MAs that had data on ThEs $(n=3)$, eight incidence estimates could be calculated; the number of RCTs included ranged from 4 to 28 , and the duration of trials ranged from 3 to 190 weeks (see Supplementary Figure S2 online, Table 1).

Cumulative incidence rates of ThEs ranged from 0.25 to $1.73 \%$ for etoricoxib; there was only one estimate for meloxicam $(0.14 \%)$.
The incidence rates of ThEs was calculated for etoricoxib only (from 0.79 to $1.37 \%$ PYs).

Heart failure (HF). From the MAs that had data on HF $(n=2)$, three incidence estimates could be calculated; the number of RCTs included ranged from 3 to 27, and the duration of trials ranged from 2 weeks to 1 year (see Supplementary Figure S3 online, Table 1).

Only cumulative incidence rates could be calculated; these ranged from 0.06 to $0.11 \%$ for celecoxib. There was only one estimate for rofecoxib $(0.62 \%)$.

\section{Incidence estimates of Gl events}

Perforation, ulcer, and bleeding (PUB). From the MAs that had data on PUB $(n=9), 22$ incidence estimates could be calculated; the number of RCTs included ranged from 2 to 20 , and the duration of trials ranged from 3 to 265 weeks (Figure 3a, Table 1).

Cumulative incidence rates of PUB ranged from 0.11 to $1.24 \%$ for etoricoxib, from 0.13 to $0.16 \%$ for meloxicam, from 0.06 to $2.6 \%$ for nabumetone, and from 0 to $0.71 \%$ for rofecoxib; there was only one estimate for etodolac $(0.42 \%)$.

Incidence rates for PUB ranged from 0.09 to $2.5 \%$ PYs for nabumetone and from 0.74 to $1.33 \%$ PYs for rofecoxib $(n=2)$; there was only one estimate for etoricoxib (1\% PYs).

Gastrointestinal bleeding (GIB). From the MAs that had data on GIB $(n=2)$, two incidence estimates could be calculated; the number of RCTs included ranged from 8 to 24 , and the duration of trials ranged from 52 to 240 weeks (Figure $3 b$, Table 1). 
Only cumulative incidence rates could be calculated, and these ranged from 2.45 to $2.98 \%$ for aspirin.

Upper gastrointestinal bleeding (UGIB). From the MAs providing data on UGIB $(n=2)$, two incidence estimates could be calculated; the number of RCTs included ranged from two to eight, and the duration of trials ranged from 4 to 26 weeks (Figure $3 \mathrm{c}$, Table 1).

Only cumulative incidence rates could be calculated, and these were $0.09 \%$ for valdecoxib and $0.18 \%$ for meloxicam.

\section{Incidence estimates for reference drugs}

Diclofenac, ibuprofen, piroxicam, and naproxen were not drugs of interest in the selected MAs; however, for these and other NSAIDs, data regarding GI and CV events were available because these were often used as reference drugs (Tables 3 and 4). However, the data on these reference NSAID drugs are not the result of a systematic retrieval process, and therefore incidence estimates are presented separately.

\section{DISCUSSION}

This systematic review provides data from MAs on 109 estimates of incidence rates for $\mathrm{CV}$ adverse events and 26 estimates of incidence rates for GI adverse events during treatment with NSAIDs. It offers a large and unique overview of the outcomes for individual NSAIDs in various situations of use (indication, treatment duration and dosage, and study population). However, the differences in these conditions of use may also limit the interpretation and comparability of the data considered in this review. For instance, all the RCTs performed to evaluate the safety profile of meloxicam in the retrieved MAs were relatively short term (most were 4 weeks, and none was $>26$ weeks) as compared with those performed for coxibs (as long as 4 years). Hence, a comparison between meloxicam and coxibs with respect to the cumulative incidence rates of GI events is not possible. Another limitation is that the same RCT could have been included in different MAs (indeed, approximately half of all reports cited were individual papers). Therefore, the estimates from different MAs are unlikely to be fully independent. Incidence rates using person-time as denominator could facilitate drug-to-drug comparisons despite the potential for bias, ${ }^{35}$ assuming that the risk would be constant. Although not elicited through a systematic search, it is interesting to note that information pertaining to NSAID-associated adverse events was more frequently available for $\mathrm{CV}$ events (for which the risk is unlikely to be constant over time) ${ }^{36}$ and less frequently available for GI events (for which the risk is expected to be more or less constant). ${ }^{37}$

An important result of this review is the identification of knowledge gaps in the GI and CV safety evaluation of individual NSAIDs in MAs, which are considered as providing the best scientific evidence ${ }^{38}$ even though they are known to be subject to publication, selection, and dissemination biases. ${ }^{39-43}$ This is of great interest given the place MAs have in evidence-based medicine to help define future areas of research. The principal knowledge gap is due to the fact that many of the existing NSAIDs were never analyzed in MAs. A deeper investigation of RCTs that have evaluated NSAIDs would reveal whether this gap is likely to be secondary to a lack of relevant RCTs for such systematic evaluation or to a lack of interest in evaluating these individual NSAIDs. An associated issue is the imbalance in the nature of the safety evaluation that can be performed from data reported in MAs. Indeed, substantially more data were available for coxibs than for tNSAIDs; also, almost no information regarding CV adverse events was associated with tNSAIDs, whereas a great amount of such data was available for coxibs. Conversely, no information was available regarding GI events for celecoxib, lumiracoxib, or parecoxib. This seems to reflect both a "period effect" and a "coxib era effect." The former is illustrated by the identification of only four MAs before 2001, all of which considered GI safety alone; these were for aspirin, ${ }^{15}$ meloxicam, ${ }^{16}$ nabumetone, ${ }^{20}$ and rofecoxib. ${ }^{24}$ We identified a greater number of MAs after 2001, when MAs began to be performed more frequently, but these were published after the concerns regarding $\mathrm{CV}$ safety were raised in regard to coxibs. ${ }^{2,3}$ Most of these MAs yielded systematic information on CV safety issues associated with the use of coxibs; this could be related to a publication or research bias: the combination of a "blockbuster event" (MI) and "blockbuster drugs" (coxibs) seems to have resulted in a "blockbuster research topic." This coxib-era effect appears to have concentrated almost all NSAID research on the systematic evaluation of CV safety of coxibs. By neglecting some other safety aspects of NSAIDs, this approach could have resulted in some of the knowledge gaps that we identified. Among these, the relative lack of evaluation of the GI safety profiles of coxibs in MAs was quite surprising, given that the demonstration of a better GI safety profile was the cornerstone of the development and marketing of coxibs and the objective of most pivotal RCTs concerning these drugs. Interestingly, this was not the case for meloxicam, which is considered a tNSAID but was the first NSAID marketed (in the 1990s) for its favorable GI safety profile. Our review identified four MAs that reported data on GI events of interest. ${ }^{12,14,16,31}$ Results such as these support the idea of a coxib-era effect; however, another possibility is that, because pivotal RCT studies of coxibs were designed with sufficient power to measure GI risk, pooled evaluations were considered unnecessary.

It was interesting to find that some clinically relevant events such as lower GI bleeding (LGIB) and hemorrhagic stroke (HS) were not evaluated in the selected MAs. The rarity of these events could explain these gaps and may reflect the intrinsic limits of RCTs to provide reliable safety information related to rare events; ${ }^{44}$ these limits may also lead to an underestimation of those for which a relatively large data set was available. Other events, such as IS, HF, and UGIB could be considered poorly studied events, the incidence of which could be estimated in only six, three, and two instances, respectively, and for a limited number of drugs (only etoricoxib for IS, celecoxib and rofecoxib for HF, and valdecoxib and aspirin for UGIB).

Knowledge gaps regarding tNSAIDs may be reduced if data for reference NSAID drugs (that are also reported here) are taken into consideration. Many MAs that investigated coxibs also reported a large amount of data for reference NSAIDs, 
the vast majority of which were tNSAIDs (mostly ibuprofen, diclofenac, and naproxen). ${ }^{9-13,18,19,22,23,25,33}$ Because these MAs included the largest RCTs available, the information provided may be considered the most clinically relevant retrievable. For many event-tNSAID pairs, data from MA reference drugs were the only data available, indicating that these were not considered in MAs investigating tNSAIDs. There are, however, many caveats related to such data. First, as the evaluation of these drugs was not the objective of MAs, the information provided did not result from a systematic process. Second, this safety information was based mostly on coxib RCTs in which tNSAID controls were often used over a long term and at high dosages (ibuprofen was most often evaluated at 2,400 mg/day, naproxen at 750-1,000 mg/ day, and diclofenac at $100-150 \mathrm{mg} /$ day).

In conclusion, this review provides a wide overview of information from MAs related to the safety profiles of NSAIDs and identifies important knowledge gaps in the systematic safety evaluation of these drugs. It underlines the limited ability to compare results obtained from different MAs, particularly with respect to rare incidence-rate estimations (i.e., PYs). In order to fill these gaps, further systematic pooled analyses of RCTs should be conducted.

\section{METHODS}

In accordance with the objectives of the SOS project, the MAs of interest were those comprising RCTs with CV and/or GI safety assessment of individual NSAIDs (either tNSAIDs, coxibs, or aspirin at $>100 \mathrm{mg} /$ day) in adults and reporting information on any of the following outcomes: (i) CV: MI, IS, hemorrhagic stroke, FS, CeV, ThE, and HF not otherwise specified (HF); (ii) GI: UGIB, LGIB, GIB not otherwise specified (GIB), and PUB. MAs that dealt with single-dose use of NSAIDs were excluded from the review.

Four electronic literature databases were searched for the identification of potentially relevant MAs: Medline, the ISI Web of Science, the Cochrane Database of Systematic Reviews, and SCOPUS. The searches were restricted to MAs published in English between January 1983 and November 2008 (inclusive). As no methods have been proposed to search the literature for MAs, an original one was developed for this study. The search strategy was first developed for Medline and then adapted to the ISI Web of Science, the Cochrane Database of Systematic Reviews, and SCOPUS (the queries used are detailed in Supplementary Appendix 3 online).

The search strategy was approved by all the authors, and the electronic search process was carried out by one review author (F.S.). Titles and abstracts were independently reviewed by two authors (F.S. and A.P.) to identify potentially relevant publications according to the criteria described above. Duplicate studies or distinct studies reporting duplicate results were excluded; in addition, MAs with estimates based on only one RCT (data point) were excluded. Disagreements were resolved through discussion. Final eligibility assessment of the potentially relevant publications was performed through examination of the full texts, obtained through the libraries of the University of Bordeaux, the French National Institute for Health and Medical Research (INSERM), and the Erasmus University Medical Center or ordered directly from the publisher. An electronic data-extraction form was used to collect the following information from the eligible publications: active compound; dose and treatment duration; number of RCTs included and indication; type of control (placebo or active comparator(s), i.e., other NSAID); number of patients or PYs included in the pooled analysis; events (type and number), and (where reported) cumulative incidence rate and/or incidence rate in PYs. The cumulative incidence or incidence rate was calculated by dividing the number of reported events by the number of exposed persons (for cumulative incidence) and by the number of PYs (for incidence rate), for both the NSAID of interest and the reference NSAID when it was an active comparator. Where the number of patients in a study was not reported in the MA, the number was calculated from the RCTs included. Confidence intervals (95\%) were calculated on the basis of Poisson or binomial distributions according to sample size and number of events. The quality of the MAs included was assessed using the QUOROM checklist. ${ }^{45}$ To measure the redundancy of MAs, the articles cited in them were identified and the number of independent articles calculated.

SUPPLEMENTARY MATERIAL is linked to the online version of the paper at http://www.nature.com/cpt

\section{ACKNOWLEDGMENTS}

The authors thank all the SOS consortium members for their fruitful suggestions and comments regarding the manuscript. The authors also thank Yannick Guillaume for his help in preparing the query searches used in this work.

\section{CONFLICT OF INTEREST}

In recent years, all the authors have conducted research and consultation funded by manufacturers of NSAIDs.

o 2011 American Society for Clinical Pharmacology and Therapeutics

1. Capone, M.L., Tacconelli, S., Di Francesco, L., Sacchetti, A., Sciulli, M.G. \& Patrignani, P. Pharmacodynamic of cyclooxygenase inhibitors in humans. Prostaglandins Other Lipid Mediat. 82, 85-94 (2007).

2. Bombardier, C. et al.; VIGOR Study Group. Comparison of upper gastrointestinal toxicity of rofecoxib and naproxen in patients with rheumatoid arthritis. VIGOR Study Group. N. Engl. J. Med. 343, 1520-1528, 2 p following 1528 (2000).

3. Silverstein, F.E. et al. Gastrointestinal toxicity with celecoxib vs nonsteroidal anti-inflammatory drugs for osteoarthritis and rheumatoid arthritis: the CLASS study: A randomized controlled trial. Celecoxib Long-term Arthritis Safety Study. JAMA 284, 1247-1255 (2000).

4. García Rodríguez, L.A. \& Barreales Tolosa, L. Risk of upper gastrointestinal complications among users of traditional NSAIDs and COXIBs in the general population. Gastroenterology 132, 498-506 (2007).

5. Egger, M., Smith, G.D. \& Phillips, A.N. Meta-analysis: principles and procedures. BMJ 315, 1533-1537 (1997).

6. Aldington, S., Shirtcliffe, P., Weatherall, M. \& Beasley, R. Systematic review and meta-analysis of the risk of major cardiovascular events with etoricoxib therapy. N. Z. Med. J. 118, U1684 (2005).

7. Aldington, S., Shirtcliffe, P., Weatherall, M. \& Beasley, R. Increased risk of cardiovascular events with parecoxib/valdecoxib: A systematic review and meta-analysis. N.Z. Med. J. 118, 1226 (2005).

8. Caldwell, B., Aldington, S., Weatherall, M., Shirtcliffe, P. \& Beasley, R. Risk of cardiovascular events and celecoxib: a systematic review and meta-analysis. J. R. Soc. Med. 99, 132-140 (2006).

9. Cannon, C.P. et al.; MEDAL Steering Committee. Cardiovascular outcomes with etoricoxib and diclofenac in patients with osteoarthritis and rheumatoid arthritis in the Multinational Etoricoxib and Diclofenac Arthritis Long-term (MEDAL) programme: a randomised comparison. Lancet 368, 1771-1781 (2006).

10. Chen, L.C. \& Ashcroft, D.M. Do selective COX-2 inhibitors increase the risk of cerebrovascular events? A meta-analysis of randomized controlled trials. J. Clin. Pharm. Ther. 31, 565-576 (2006).

11. Chen, L.C. \& Ashcroft, D.M. Risk of myocardial infarction associated with selective COX-2 inhibitors: meta-analysis of randomised controlled trials. Pharmacoepidemiol. Drug Saf. 16, 762-772 (2007).

12. Chen, Y.F. et al. Cyclooxygenase-2 selective non-steroidal anti-inflammatory drugs (etodolac, meloxicam, celecoxib, rofecoxib, etoricoxib, valdecoxib and lumiracoxib) for osteoarthritis and rheumatoid arthritis: a systematic review and economic evaluation. Health Technol. Assess. 12, 1-278, iii (2008).

13. Curtis, S.P., Ko, A.T., Bolognese, J.A., Cavanaugh, P.F. \& Reicin, A.S. Pooled analysis of thrombotic cardiovascular events in clinical trials of the COX-2 selective Inhibitor etoricoxib. Curr. Med. Res. Opin. 22, 2365-2374 (2006).

14. Degner, F. \& Richardson, B. Review of gastrointestinal tolerability and safety of meloxicam. Inflammopharmacology 9, 71-80 (2001).

15. Derry, S. \& Loke, Y.K. Risk of gastrointestinal haemorrhage with long term use of aspirin: meta-analysis. BMJ 321, 1183-1187 (2000). 
16. Distel, M., Mueller, C., Bluhmki, E. \& Fries, J. Safety of meloxicam: a global analysis of clinical trials. Br. J. Rheumatol. 35 (suppl. 1), 68-77 (1996)

17. Edwards, J.E., McQuay, H.J. \& Moore, R.A. Efficacy and safety of valdecoxib for treatment of osteoarthritis and rheumatoid arthritis: systematic review of randomised controlled trials. Pain 111, 286-296 (2004).

18. Garner, S.E., Fidan, D.D., Frankish, R. \& Maxwell, L. Rofecoxib for osteoarthritis. Cochrane Database Syst. Rev. CD005115 (2005).

19. Goldstein, J.L., Eisen, G.M., Agrawal, N., Stenson, W.F., Kent, J.D. \& Verburg, K.M. Reduced incidence of upper gastrointestinal ulcer complications with the COX 2 selective inhibitor, valdecoxib. Aliment. Pharmacol. Ther. 20, 527-538 (2004).

20. Huang, J.Q., Sridhar, S. \& Hunt, R.H. Gastrointestinal safety profile of nabumetone: a meta-analysis. Am. J. Med. 107, 55S-61S; discussion 61S (1999).

21. Jüni, P., Nartey, L., Reichenbach, S., Sterchi, R., Dieppe, P.A. \& Egger, M. Risk of cardiovascular events and rofecoxib: cumulative meta-analysis. Lancet 364 2021-2029 (2004).

22. Kearney, P.M., Baigent, C., Godwin, J., Halls, H., Emberson, J.R. \& Patrono, C. Do selective cyclo-oxygenase- 2 inhibitors and traditional non-steroidal antiinflammatory drugs increase the risk of atherothrombosis? Meta-analysis of randomised trials. BMJ 332, 1302-1308 (2006).

23. Konstam, M.A. et al. Cardiovascular thrombotic events in controlled, clinical trials of rofecoxib. Circulation 104, 2280-2288 (2001).

24. Langman, M.J. et al. Adverse upper gastrointestinal effects of rofecoxib compared with NSAIDs. JAMA 282, 1929-1933 (1999).

25. Matchaba, P. et al. Cardiovascular safety of lumiracoxib: a meta-analysis of all randomized controlled trials $>$ or $=1$ week and up to 1 year in duration of patients with osteoarthritis and rheumatoid arthritis. Clin. Ther. 27, 1196-1214 (2005).

26. Moore, R.A., Derry, S., Makinson, G.T. \& McQuay, H.J. Tolerability and adverse events in clinical trials of celecoxib in osteoarthritis and rheumatoid arthritis: systematic review and meta-analysis of information from company clinical trial reports. Arthritis Res. Ther. 7, R644-R665 (2005).

27. Ramey, D.R., Watson, D.J., Yu, C., Bolognese, J.A., Curtis, S.P. \& Reicin, A.S. The incidence of upper gastrointestinal adverse events in clinical trials of etoricoxib vs. non-selective NSAIDs: an updated combined analysis. Curr. Med Res. Opin. 21, 715-722 (2005).

28. Serebruany, V.L. et al. Analysis of risk of bleeding complications after different doses of aspirin in 192,036 patients enrolled in 31 randomized controlled trials. Am. J. Cardiol. 95, 1218-1222 (2005).

29. Singh, G., Lanes, S. \& Triadafilopoulos, G. Risk of serious upper gastrointestinal and cardiovascular thromboembolic complications with meloxicam. Am.J. Med. 117, 100-106(2004).

30. Solomon, S.D. et al.; APC and PreSAPTrial Investigators. Effect of celecoxib on cardiovascular events and blood pressure in two trials for the prevention of colorectal adenomas. Circulation 114, 1028-1035 (2006).
31. Tavakoli, M. Modelling therapeutic strategies in the treatment of osteoarthritis: an economic evaluation of meloxicam versus diclofenac and piroxicam. Pharmacoeconomics 21, 443-454 (2003).

32. Watson, D.J., Yu, Q., Bolognese, J.A., Reicin, A.S. \& Simon, T.J. The upper gastrointestinal safety of rofecoxib vs. NSAIDs: an updated combined analysis. Curr. Med. Res. Opin. 20, 1539-1548 (2004).

33. White, W.B., Faich, G., Borer, J.S. \& Makuch, R.W. Cardiovascular thrombotic events in arthritis trials of the cyclooxygenase-2 inhibitor celecoxib. Am. J. Cardiol. 92, 411-418 (2003).

34. White, W.B., Strand, V., Roberts, R. \&Whelton, A. Effects of the cyclooxygenase-2 specific inhibitor valdecoxib versus nonsteroidal antiinflammatory agents and placebo on cardiovascular thrombotic events in patients with arthritis. Am. J. Ther. 11, 244-250 (2004).

35. Rosso, S., Ricceri, F., Terracini, L. \& Zanetti, R. Methodological issues in estimating survival in patients with multiple primary cancers: an application to women with breast cancer as a first tumour. Emerg. Themes Epidemiol. 6, 2 (2009).

36. Lévesque, L.E., Brophy, J.M. \& Zhang, B. The risk for myocardial infarction with cyclooxygenase- 2 inhibitors: a population study of elderly adults. Ann. Intern. Med. 142, 481-489 (2005)

37. Ravaud, P. \& Chaussade, S. [NSAIDs digestive risk: epidemiologic data]. Presse Med. 32, S5-S8 (2003).

38. Guyatt, G. \& Drummond, R. Users' Guides to the Medical Literature: AManual for Evidence-Based Clinical Practice (AMA Press, Chicago, IL, 2002).

39. Carpenter, J., Rücker, G. \& Schwarzer, G. Assessing the sensitivity of metaanalysis to selection bias: a multiple imputation approach. Biometrics (2010); e-pub ahead of print 29 October 2010.

40. Peters, J.L., Sutton, A.J., Jones, D.R., Abrams, K.R. \& Rushton, L. Comparison of two methods to detect publication bias in meta-analysis. JAMA 295, 676-680 (2006)

41. Bowden, J., Jackson, D. \& Thompson, S.G. Modelling multiple sources of dissemination bias in meta-analysis. Stat. Med. 29, 945-955 (2010).

42. Williamson, P.R. \& Gamble, C. Identification and impact of outcome selection bias in meta-analysis. Stat. Med. 24, 1547-1561 (2005)

43. Hahn, S., Williamson, P.R., Hutton, J.L., Garner, P. \& Flynn, E.V. Assessing the potential for bias in meta-analysis due to selective reporting of subgroup analyses within studies. Stat. Med. 19, 3325-3336 (2000).

44. Goldman, S.A., Kennedy, D.L. \& Lieberman, R.L. A MedWatch Continuing Education Article. Clinical Therapeutics and the Recognition of Drug-induced Disease <http://www.fda.gov/downloads/Safety/MedWatch/UCM168515. pdf $>$ (1995).

45. Moher, D., Cook, D.J., Eastwood, S., Olkin, I., Rennie, D. \& Stroup, D.F. Improving the quality of reports of meta-analyses of randomised controlled trials: the QUOROM statement. Quality of Reporting of Meta-analyses. Lancet 354 1896-1900 (1999). 